\title{
Algunos procedimientos de cohesión textual para mejorar las estrategias comunicativas del discurso oral
}

ISABEL PAULO SELVI

IES Els Évols

46021320@edu.gva.es

\begin{abstract}
Resumen: La dificultad de la destreza de la expresión oral se debe a causas emocionales, cognitivas, didácticas y lingüísticas. Diferentes trabajos se han orientado hacia la oralidad, quizás, porque el estudio del habla funciona como una forma dinámica de comunicación; sin embargo, el prestigio de la lengua escrita y el desconocimiento de la lengua oral han tenido efectos perniciosos con modelos artificiales para la enseñanza de ELE.
\end{abstract}

La propuesta se centra en trabajar algunos procedimientos de cohesión textual con la intención de mejorar las estrategias comunicativas del discurso oral. Se trata de elaborar una secuencia pedagógica donde se expone una muestra de lengua contextualizada en la que aparecen los contenidos que se desean que los alumnos aprehendan, se plantean actividades y se reflexiona a través de un discurso modalizado cercano al mundo referencial del discente.

Palabras clave: cohesión textual, discurso oral, secuencia pedagógica.

\section{Some procedures of textual cohesion to improve the communicative strategies of oral discourse}

Abstract: The difficulty of the skill of oral expression is due to emotional, cognitive, didactic and linguistic causes. Different works have been oriented towards orality, perhaps, because the study of speech works as a dynamic form of communication; However, the prestige of the written language and the ignorance of the oral language have had pernicious effects with artificial models for teaching ELE.

The proposal focuses on working on some procedures of textual cohesion with the intention of improving the communicative strategies of oral discourse. The aim is to develop a pedagogical sequence where a sample of contextualized language is exhibited in which the contents that students wish to learn are displayed, activities are presented and reflected through a modalized discourse close to the referential world of the learner.

Keywords: textual cohesion, oral discourse, pedagogical sequence.

\section{La dificultad de la expresión oral}

La destreza de la expresión oral se considera una de las más difíciles si la comparamos con otras, quizás, más seguras para el hablante de ELE. Por ello, algunos autores argumentan que los alumnos tienen que tener claro los objetivos de la tarea, su finalidad y el modo en que se organiza la actividad para poder involucrarse en ella (Gelabert, Bueso y Benítez, 2012: 39); además de contar con propuestas abiertas, significativas y cercanas a su mundo referencial. La dificultad del discurso oral es debido a diferentes 
causas, entre las cuales se destaca las emocionales, cognitivas y didácticas (Duque 2016). Se puede considerar que la vergüenza, la falta de motivación, el valor cultural al hecho de hablar o las tradiciones heredadas en la enseñanza de idiomas constituyen razones emocionales suficientes para que se aparte del acto comunicativo, en un intento de no-exposición que ponga en peligro la imagen personal o simplemente que evidencie un escaso dominio lingüístico. También puede tratarse de un desconocimiento del sistema lingüístico o temático, el cual impida tener una opinión formada para intervenir cuando el hablante intenta exponer algo en público.

Las razones didácticas se centran en la insuficiente planificación y clarificación de las actividades por parte del docente o en esa relación interpersonal ya jerarquizada de antemano por un emisor privilegiado que corrige excesivamente (o no corrige nada), que habla demasiado o que impone ciertas reglas en niveles bajos de competencia lingüística (me refiero en la interconexión vehicular entre la lengua materna y la lengua meta). En este estado de cosas, proponer soluciones no es tarea fácil. Para Ravera Carreño (1990: 23-25) todas las actividades de expresión oral tienen que tener unos principios básicos. Es conveniente realizar actividades afectivas sencillas donde el docente colabore y fomente las libertades expresivas para desarrollar las destrezas y la relación establecida entre el docente y su grupo. Es recomendable que el profesor guíe a sus estudiantes con recursos de ayuda o que manifieste una actitud positiva con los logros conseguidos, fomentando así la autoestima.

Para solucionar las razones cognitivas es necesario ofrecer opciones o citas sobre el tema, dar más tiempo a ciertos alumnos, o hacer guiones y mapas conceptuales. Si se observa una carencia de recursos en el hablante, se pueden desarrollar estrategias de compensación, cambiar actividades, proponer modelos y actividades mediadoras $u$ otros recursos. A veces lo interesante no es realizar una actividad propuesta y planificada por el docente sino dar la oportunidad de abrir un debate espontáneo sobre la misma, incluso para criticarla. Es conveniente que el alumno conozca su entorno inmediato a través del vocabulario preciso y de la manera más visual posible, con actividades centradas en la práctica comunicativa, puesto que todas estas estrategias de intervención facilitarán la participación en el aula.

\section{La importancia del relato conversacional}

Una de las características de la conversación coloquial es la aparición de las secuencias de historia (Gallardo 1993, 1996) o relatos conversacionales (Briz, 2004). Estas estrategias discursivas, frecuentemente dramatizadas, se realizan como auténticos diálogos o reflexiones del sujeto hablante. En este sentido, los enunciados constituyen dos maneras de representación de la realidad:

Dicho de otro modo, en el caso de que el enunciado represente un pensamiento del hablante sobre un estado de cosas, tendremos una descripción; de otra manera, si el enunciado representa el pensamiento del hablante sobre otro enunciado o pensamiento que el hablante trata de representar, nos encontramos con una interpretación. (Benavent Payà, 2016: 228)

En esta combinación pragmático-discursiva se integra el componente suprasegmental tratado profundamente por diversos autores (Hidalgo 1997, 2007, 2010; Hidalgo y Padilla 2006). El modelo funcional del Grupo Val.Es.Co. (2014: 16) se basa en una serie de propiedades entre las cuales destaca un sistema estructurado en niveles y 
dimensiones. Los primeros inciden en el doble carácter monológico y dialógico del discurso; los segundos se proyectan en tres dimensiones: social, estructural e informativa. Esta organización y delimitación de unidades sirve de marco para poder analizar un determinado fragmento del discurso oral, y en este sentido las partículas discursivas no solamente sirven para la conexión de segmentos sino también para vincular todo el proceso de aprendizaje (Briz y Pons 2010, Estellés y Pons 2014).

Para el estudiante de ELE es difícil comunicar bien de forma oral, porque el registro coloquial se adquiere en los niveles más avanzados (Cinzia di Franco, 2016: 285), además, es importante que el discente domine los mecanismos de cohesión textual para que su discurso oral no se vea empobrecido. Muchos estudios lingüísticos han tratado el tema de los marcadores discursivos tanto desde su morfología como de su gramaticalidad, e incluso en su dimensión de poder social (Martín Zorraquiño 1998, 2010; Pons Bordería 1998, 2008, 2014), pero es necesario llevar estos mecanismos discursivos al aula con textos orales cercanos al mundo referencial del alumno. Conseguir una competencia comunicativa es complejo, y más si cabe cuando esto implica un conocimiento del código lingüístico, de sus unidades y de sus combinaciones (competencia gramatical), la capacidad de entender y producir textos en relación con factores contextuales (competencia pragmática), y el de combinar formas y significados que den lugar a un texto coherente y cohesionado (competencia discursiva). Asimismo, hay que destacar el interés por parte del discente en conseguir un buen nivel de pronunciación para desarrollar destrezas orales efectivas y eficaces en la comunicación (Agustín Llach 2004: 5).

\section{Secuencia p-p-p}

Diferentes trabajos se han orientado hacia la oralidad, quizás, porque el estudio del habla funciona como una forma dinámica de comunicación (Díez Domínguez 2008; Nogueira 2011; Hernández 2008; Domenech 2008; Campillos 2010, 2014); sin embargo, el prestigio de la lengua escrita y el desconocimiento de la lengua oral ha tenido efectos perniciosos en la enseñanza de ELE. Todavía hay modelos de la enseñanza de la lengua oral artificiales que figuran en los manuales.

La secuencia se centra en una de las peculiaridades del registro coloquial que nos invita a reflexionar sobre la lengua. Se trata de una situación comunicativa donde una estudiante alemana de Erasmus ha preparado un video para explicar Cómo ve a los españoles. Esta exposición oral demuestra una visión muy subjetiva del hablante, puesto que se trata de una imagen estereotipada. Este modelo de discurso oral es una Realia cercana al alumno de ELE, con el cual puede sentirse identificado, además de ser un vehículo excelente para mejorar la competencia de la expresión oral.

\subsection{Enfoque}

Dentro de la enseñanza comunicativa se adoptará un enfoque por tareas en la que se elabora una secuencia pedagógica P-P-P. Esta consiste en presentar el contenido dentro de un contexto en el aula, es decir, se expone la muestra de lengua contextualizada en la que aparece los contenidos que se desea que los alumnos aprehendan; se plantean actividades con apoyo o modelo, de escasa carga cognitiva, que les proporcionan la oportunidad de automatizar esos contenidos presentados, muchas veces mediante el trabajo en parejas o pequeños grupos; y finalmente, se plantean actividades sin apoyo o con modelo en un contexto determinado, donde los alumnos ponen en práctica, de 
forma más o menos controlada, los contenidos que han automatizado en la fase anterior, es decir, una tarea extralingüística que permite una segunda supervisión evaluativa.

\subsection{Perfil del alumnado}

Se trata de un alumnado que dentro del Marco Común Europeo de Referencia de las Lenguas (MCERL) realiza descripciones y presentaciones detalladas sobre un tema complejo, integrando otros temas, desarrollando ideas concretas y terminando con una conclusión adecuada. Este tipo de alumnado ya ha adquirido una competencia comunicativa, tiene una pronunciación inteligible y puede expresar matices sutiles de significado. Es capaz de realizar actividades de lengua observables y de poner en práctica estrategias de comunicación.

\subsection{Objetivos de aprendizaje}

Los objetivos serán los siguientes:

-Mejorar las estrategias comunicativas.

-Organizar de manera cohesionada el discurso oral.

-Analizar algunos mecanismos de cohesión textual.

\subsection{Temporalización}

Proponemos una serie de actividades distribuidas en tres sesiones de trabajo de 60 minutos cada una, las dos primeras sucesivas y la tercera después de dos días (porque la tarea de los alumnos requiere un trabajo fuera del aula).

\subsection{Secuencia didáctica}

La primera sesión se estructura en dos fases: la primera es una presentación del tema con el visionado del video de la estudiante alemana; la segunda, unas prácticas guiadas.

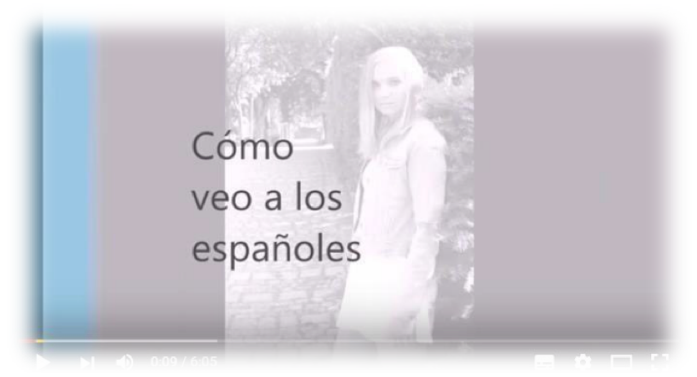

Fig. 1. Disponible en: https://www.youtube.com/watch?v=PTXMfj1r9V4

El visionado se presenta con ligeras pausas que corresponden a los inicios de cada tema. Esto nos servirá para trabajar después las actividades de mecanismos de sustitución y de procedimientos de cohesión textual. También es un buen momento para que los discentes puedan sugerir qué creen que va a decir la estudiante alemana e involucrarse en su discurso.

La segunda fase conlleva unas prácticas guiadas que permiten, en una dinámica asamblearia, reflexionar sobre cada una de las actividades de lengua de carácter comunicativo y pragmático, así como introducir el componente sociocultural en el aula. 


\subsubsection{Primera práctica}

El discurso oral de la estudiante alemana se transforma en texto escrito y se presenta de manera fragmentada. Se pide a los estudiantes (distribuidos en grupos) que intenten recomponerlo siguiendo el orden lógico del discurso y justificándolo. El objetivo de la práctica es doble, por una parte comprobar que el discente es capaz de ordenar de manera coherente el discurso oral y, por otra, trabajar los elementos cohesivos que le han permitido organizarlo. Las piezas que tienen que recomponer están en tarjetas y corresponden a los siguientes fragmentos:

(1) Otra cosa es que los españoles hablan de voz alta siempre, en fiestas grita toda la gente y hace tanto ruido y en cada sitio público, la gente está gritando, me parece. Siempre se oye la voz de la gente, la gente hablando y no es así en Alemania. Si estás en el aeropuerto de Alemania hay silencio.

(2) Eso es todo lo que quise decir hoy sobre los españoles. Espero que os guste el vídeo y decidme si queréis que haga más videos en español o que queráis. Hasta luego, chicos.

(3) Empezamos. Pienso que los españoles son en general bastantes bajos. Yo soy alta, un metro setenta y cuatro. Y en Alemania no me parece demasiado alta, pero en España me pareció, que era muy muy alta, muy mucho más alta que muchos chicos. Vale. Soy bastante alta y soy rubia y entonces yo era diferente que los otros, pero no pasa nada.

(4) Vale. ¿Qué más? También hay una cosa rara que hacen los españoles es la pronunciación de palabras ingleses. Los alemanes pronunciamos las palabras de manera inglés si son palabras ingleses, pero los españoles pronuncian las palabras ingleses en español, entonces no entiendes las palabras, a veces son super raras.

(5) Sí. Otra cosa que me gustó mucho era la marcha. Creo que siempre está gente en la calle, las familias pasan las tardes en la calle juntos cenando. Vale, hace mejor tiempo en España pero también es la cultura de los españoles. Creo que a ellos les gusta estar en la calle, y pasar tiempo juntos en la calle. Es diferente a Alemania.

(6) La última cosa que quiero decir es que creo que los españoles son más abiertos que los alemanes. Si hablas una persona española te ayuda y te hace más preguntas y son muy abiertos y es más fácil hacer una correlación con desconocidos en España, si sabes español claro, porque los alemanes te solo dan una respuesta corta y después no se interesan más.

(7) Hola, soy Patricia, y hoy voy a hacer un video en español. Es que hice un Erasmus en Madrid y me enamoré de la gente, de la lengua y de todo en España; por eso, sigo pensando en español a veces, y por eso quiero hacer un video en español. Este video es sobre españoles, quiero deciros que he visto, que me di cuenta en España, y comparar las culturas de Alemania y España, un poco.

(8) Otra diferencia es que en España todo pasa más tarde. Te levantas más tarde, comes más tarde, trabajas más tarde y cenas mucho más tarde. En general, todo pasa más tarde.

(9) ¿Qué más? Una cosa que es diferente para mí también es cómo saludarse. Los alemanes nos damos la mano a desconocidos y en España se dan dos BESOS. Cuando das dos besos estás muy cerca de la otra persona que a los alemanes parece bastante seca, pero si digo a los españoles que en Alemania abrazamos a nuestros amigos, dicen que esto es muy íntimo, para nosotros eso es normal.

(10) Otra cosa de que me di cuenta es que los españoles viven más tiempo en su familia, en Alemania no es normal. Si empiezas la universidad mucha gente se va a vivir en un piso compartido o algo así. En España vives con tu familia, con tus padres si estudias en la misma ciudad. Si estudias en otra ciudad, vives con otra parte de tu familia, como tu tía por ejemplo, que no sería así en Alemania, vivirías sola o con gente de tu edad.

(11) La próxima cosa, la gente española es más caótica y menos organizada, pero también así son más flexibles, me parece. 
(12) Otra cosa es que la gente en España no come en la calle, no te compras algo y lo comes en camino. En Alemania se hace, estamos más deprisa y por eso si no nos da tiempo a comer lo llevamos y lo comemos en la calle sin problema o en un transporte público; pero si vas en metro de Madrid y comes algo, ves que nadie come. La gente española se toma el tiempo para comer, se siente y tranquilamente come sin prisa. ¡Es increíble que son tan relajados! Los alemanes, no.

Después de haber recompuesto el texto, el profesor les pasará el texto completo de la estudiante alemana e irán comprobando sus aciertos. El objetivo de la actividad es observar el uso recurrente de la misma estructura en los inicios y buscar otros mecanismos de sustitución de la proforma léxica.

\subsubsection{Segunda práctica}

El docente trabajará los marcadores discursos teniendo presente dos clases de mecanismos: por una parte, aquellos marcadores de función pragmática (que hacen referencia a los elementos de la comunicación que están implicados en el texto: vocativos, apelaciones al destinatario, ciertos elementos de función fática, adverbios y sintagmas preposicionales); por otra parte, los de función textual (que establecen conexiones entre los distintos enunciados o párrafos de un texto). Se tiene que tener en cuenta la importancia de los organizadores de la argumentación y los mecanismos cohesivos que permiten introducir una opinión personal ("en mi opinión, para mí, tal como lo veo yo, estoy convencido de que"...), dar una información sin responsabilizarse de su veracidad ("según dicen, dicen que, según parece, he oído que"..), añadir argumentos o insistir en un aspecto de nuestra argumentación ("en el fondo, la verdad es que, lo cierto es que, a fin de cuentas"), o resumir y concluir ("en resumen, total que, en fin que"..).

Los mecanismos lógico-sintácticos aportan coherencia al texto, guían la interpretación del discurso y contribuyen a la coherencia informativa (Llopis 2014: 33). La gran abundancia de terminología (tratados como conectores, elementos, partículas, enlaces extraoracionales, partículas discursivas, marcadores) ha sido uno de los inconvenientes hasta llegar a una sistematización a través de la clasificación funcional (Pons 2001, 2006). Ahora bien, todavía hay problemas cuando se analizan los marcadores discursivos alejados de su información sintáctico-discursiva, su ámbito de actuación y su función conectora. El docente proyectará un modelo asequible para que los discentes puedan aplicarlo en su producción posterior:

Presentación: para empezar, (ante todo, bueno, bien...)

Continuación: luego, después (pues bien, así que, en cuanto a...)

Transición: por una parte.... por otra parte...

Digresión: por cierto (a propósito)

Enumeración: en primer lugar, en segundo lugar, por último (por un lado, por el otro...).

Cierre: finalmente, para finalizar (en fin, para acabar...)

Figura 2. Cuadro de organizadores textuales. 
Con todo ello, los discentes pueden reflexionar sobre el uso de los marcadores organizativos de la estudiante alemana y ver las posibilidades de sustitución léxica de la proforma, así como las estructuras de opinión empleadas.

\subsubsection{Tercera práctica}

El visionado del discurso oral sirve para trabajar el componente intercultural del estereotipo con un doble objetivo: por un lado, realizar una toma de conciencia de algunos estereotipos nacionales; por otro, tener una visión crítica de los mismos. La chica alemana afirmaba que «los españoles siempre hablan gritando, se levantan tarde, siempre están de marcha, son caóticos y nada organizados, son extrovertidos y prestan ayuda a los extranjeros». En plenaria se debate la imagen que tiene la estudiante alemana sobre la marca España y se proyectan dos bloques de imágenes con carga estereotipada diferente (todas ellas pertenecen a España).
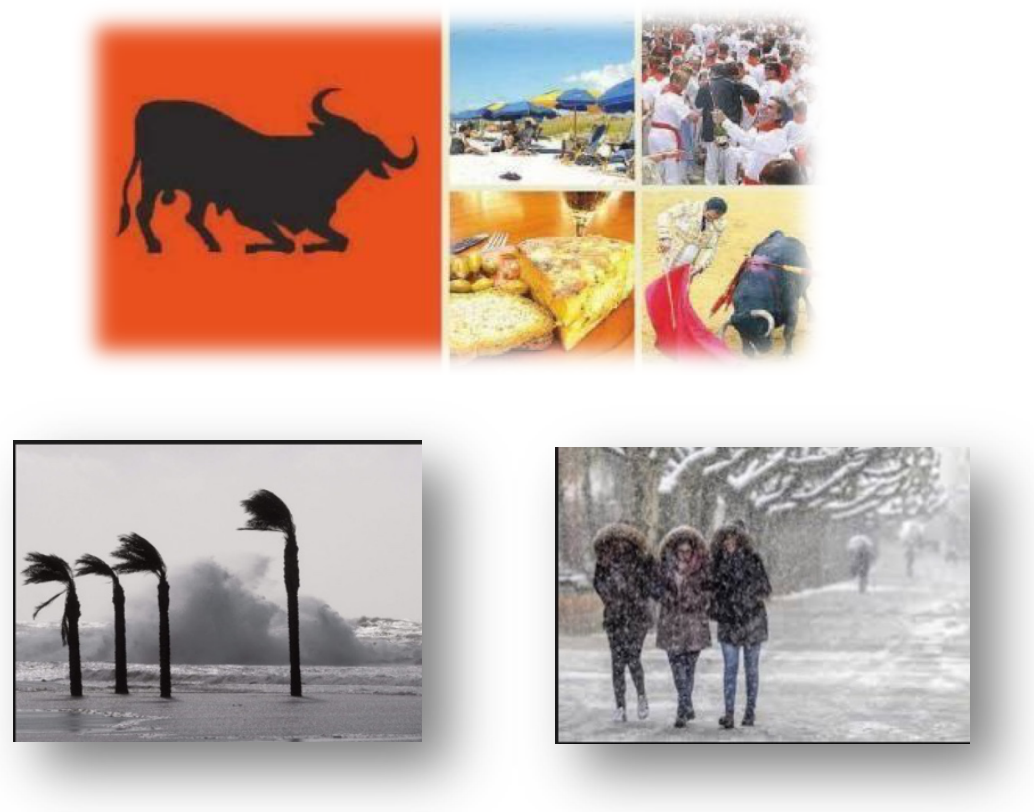

Figura 3. Imágenes para trabajar los estereotipos.

La diversidad cultural de la clase es una fuente de enriquecimiento para reducir la influencia de las posturas etnocéntricas e incorporar nuevos conocimientos culturales con la finalidad de desmontar estereotipos. Se pretende que los alumnos tomen conciencia de que la perspectiva de su identidad cultural (en este caso los estereotipos de nacionalidades) influye en la interpretación de otras culturas, además de reconocer similitudes y diferencias en ese componente sociocultural (ver cuestionario en el Anexo 1).

En la segunda sesión los alumnos elaborarán un video siguiendo el modelo realizado por la estudiante alemana pero mejorando los problemas de cohesión textual que tenía la protagonista. El discurso oral se caracterizará por la adecuación al contexto comunicativo, la coherencia informativa y su cohesión lineal.

Desde la doble perspectiva en la que se enfoca las propiedades textuales (interpretación y producción) los procedimientos de cohesión son fundamentales, no solamente porque 
ayudan a entender el sentido global del texto sino porque nos sirven para elaborar los nuestros, por eso la presencia de conectores, que nos marcan las partes constitutivas o las relaciones lógicas entre las ideas, facilita la tarea de comprender lo que el emisor nos quiere transmitir y cómo se organiza esa información. En este sentido el docente habrá insistido en la importancia de los conectores que estructuran y organizan el discurso, en aquellos que estructuran las ideas y en los que introducen operaciones discursivas o pragmáticas que orientan sobre el tratamiento de la información, y por tanto nos sirven para tematizar, aclarar o reformular o ejemplificar.

La tercera sesión se dedicará a ver los videos que han realizado los alumnos como tarea final. El docente pasará una ficha en la que se compruebe que los contenidos se han interiorizado. Lo ideal es que los alumnos la tengan en una plantilla donde figure el nombre del alumno y unos ítems muy básicos para que mientras el material se visualiza se pueda completar.

\begin{tabular}{|l|l|l|l|}
\hline Organizadores & & & \\
\hline Lógicos & & & \\
\hline Pragmáticos & & & \\
\hline
\end{tabular}

Figura 4. Ficha de marcadores. Fuente propia.

\section{Conclusiones}

Es necesario trabajar el discurso oral con estrategias focalizadas en mecanismos lógicosintácticos y tener en cuenta un análisis de los marcadores discursivos que evidencien su estructura informativa y su carácter polifónico. La estudiante alemana adolecía de recursos para evitar la constante recurrencia de la proforma léxica, y en consecuencia, su exposición oral fallaba en la cohesión textual.

Los elementos que entran en conexión por medio de un marcador discursivo son heterogéneos, por ello es aconsejable no solamente integrar sintácticamente las estructuras sino también explicitar las relaciones pragmáticas; de esta manera se podrá conseguir un discurso más cohesionado y entendible.

La secuencia pedagógica también favorece una disposición favorable y consciente hacia otras realidades culturales desde una perspectiva alejada de posturas etnocéntricas, juicios de valor, estereotipos y prejuicios.

\section{Bibliografía}

Agustín Llach, María Pilar (2004). La importancia de la lengua oral en la clase de ELE: estudio preliminar de las creencias de aprendices. La Rioja: Universidad de la Rioja.

BENAVENT PAYÀ, Elisa (2016). "Decir" y discurso directo en los relatos de la conversación coloquial. Valencia: Universidad de Valencia.

BRIZ GÓMEZ, Antonio (2004). «El español coloquial. ¿Por qué comenzar su análisis en clase? », Mosaico. Revista para la promoción y apoyo a la enseñanza del español, 14, (pp.4-6). Consejería de Educación en Bélgica, Países Bajos y Luxemburgo. 
BRIZ GómEZ, Antonio y Salvador PONS BORDERÍA (2010). «Unidades, marcadores discursivos y posición». En Ó. Loureda y E. Acín (coords.); Los estudios sobre marcadores del discurso en español, hoy (pp. 327-358). Madrid: Arco/ Libros.

Campillos Llanos, L. et al. (2010). Español oral en contexto. Vol. 1. Textos de español oral. Material de ELE basado en corpus. Comprensión auditiva. Madrid: Servicio de publicaciones de la Universidad Autónoma de Madrid.

Campillos Llanos, L., y P. Gozalo Gómez (2014). «Oral production of discourse markers by intermediate learners of Spanish: a corpus perspective». En J. Romero-Trillo (ed.); Yearbook of Pragmatics and Corpus Linguistics 2014: New Empirical and Theoretical Paradigms (pp. 239-259). New York: Springer.

CINZIA DI FRANCO (2006). «La enseñanza de la expresión oral en la clase de ELE». XVII Congreso Internacional de la Asociación del Español como lengua extranjera (ASELE). (pp.469-482). Logroño: Universidad de la Rioja.

DUQue, Eladio (2016). Las relaciones de discurso. Cuadernos de lengua española. Madrid: Arco/Libros.

Gelabert Navarro, María José, Isabel Bueso Fernández y Pedro Benitez Pérez (2012). Producción de materiales para la enseñanza del español. Madrid: Arco/Libros.

GRUPO VAL.Es.CO. (2014). «Las unidades del discurso oral», Estudios de Lingüística del Español (pp. 11-71). Valencia: Universidad de Valencia.

HidAlgo NAVARro, Antonio (1997). «La entonación coloquial. Función demarcativa y unidades de habla», Anejo XXI de la revista Cuadernos de Filología (pp. 324-345). Valencia: Universidad de Valencia.

HidAlgo NAVARRO, Antonio (2003). «Microestructura discursiva y segmentación informativa en la conversación coloquial», ELUA, 17 (pp. 367-385). Alicante: Universidad de Alicante.

HidAlgo NAVARRo, Antonio (2004). «Las unidades de la conversación: acto y subacto como segmentos menores del análisis», Actas del VI Congreso de Lingüistica General (pp. 3365-3380). Santiago de Compostela: Arco/Libros.

HidAlgo NAVARRO, Antonio (2007). «La prosodia como principio estructurador e interpretativo del discurso oral". Discurso y Oralidad». En L. Cortés y otros (eds.); Homenaje al profesor J.J. de Bustos Tovar. Volumen II. (pp. 567-582). Madrid: Arco/Libros.

HidAlgo NAVARRO, Antonio (2010). «Los marcadores del discurso y su significante: en torno a la interfaz marcadores-prosodia en español». En Ó. Loureda y E. Acín (coords.) Los estudios sobre marcadores del discurso en español, hoy, (pp. 61- 92). Madrid: Arco/Libros.

Hidalgo Navarro, Antonio y Xose Padilla García (2006). «Bases para el análisis de las unidades menores del discurso oral: los subactos», Oralia, vol. 9, (pp.109-144). Madrid: Arco/Libros.

Llopis CARDONA, Ana (2014). Aproximación funcional a los marcadores discursivos. Análisis y aplicación lexicográfica. Frankfurt am Main: Peter Lang 
MARTín ZorRAQUiÑo, Ma Antonia y Estrella Montolío DURÁn (eds.) (1998). Los marcadores del discurso. Teoría y análisis. Madrid: Arco/Libros.

MARTÍN ZORRAQUiÑo, M ${ }^{\mathrm{a}}$ Antonia (2010). «Los marcadores del discurso y su morfología». En Loureda Lamas y Acín Villa (coords.); Los estudios sobre los marcadores del discurso en español, hoy (pp. 3-181). Madrid: Arco/Libros.

PONS BORDERÍA, Salvador (1998). «Conexión y conectores. Estudio de su relación en el registro informal de la lengua», (pp.1-241). Anejo XXVII de la revista Cuadernos de Filología, Valencia: Universidad de Valencia.

PONS BORDERÍA, Salvador (2008). «La combinación de marcadores del discurso en la conversación coloquial: interacciones entre posición y función», Estudos Linguísticos/ Linguistic Studies, 2, (pp.141-159). Lisboa, Ediçoes Colibri/ CLUNL.

PONS BORDERÍA, Salvador (2014). "Models of discourse segmentation in Romance languages: An overview». En S. Pons Bordería (ed.);(pp.1-21). Discourse Segmentation in Romance Languages. John Benjamins, Publishing Company.

RAVERA CARREÑO, M. (1990) «La expresión oral: teoría, tendencias y actividades». Didáctica de las segundas lenguas AAVV, (pp.13-42). Madrid: Santillana.

\section{Anexo 1}

1. ¿Cómo has conocido la cultura española?

2. Expresa 6 características de la manera de ser de tus conciudadanos según tu percepción.

3. Indica 5 realidades, aspectos u objetos (materiales o no) que consideres representativos de tu cultura.

4. Indica 5 realidades, aspectos u objetos que consideres representativos de la cultura española.

5. ¿El conocimiento que has adquirido de la lengua y de la cultura española ha influido en tu visión de las cosas, en el sistema de valores, etc.?

6. ¿Crees que los comportamientos o maneras de ser de los españoles difieren de tus conciudadanos?

7. ¿Qué aspectos culturales de la sociedad española crees que van a facilitar tu integración en ella? ¿En qué razones te basas?

8. ¿Qué aspectos de la vida española pueden entorpecer tu integración en ella? ¿Qué razones te llevan a creerlo?

9. ¿Crees que los estereotipos de España presentan una imagen positiva o negativa? (explica las razones)

10. ¿Crees que con esta sesión has desmontado varios estereotipos? ¿En qué sentido? 